\title{
Kebutuhan Air untuk Tanaman Terung ( Solanum melongena. L) pada Lempung Liat Berpasir di Tanah Ultisols
}

\author{
Water Requirement for Eggplant (Solanum melongena. L) on Sandy Clay Loam of Ultisols
}

\author{
Ratna Shanti \\ Tenaga Pendidik Program Studi Agroteknologi, Fakultas Pertanian, Universitas Mulawarman \\ Jl. Pasir Balengkong Kota Samarinda, Kalimantan Timur 75117 \\ Email : ratnasanti.msi@gmail.com
}

Diterima : 4 April 2019 Disetujui : 17 Juni 2019

\begin{abstract}
The purpose of this study was to determine optimum water requirement of eggplant (Solanummelongena L) onsandy clay loam soil of Ultisols during it growth period. The experiment was conducted on $5^{\text {th }}$ May to $27^{\text {th }}$ Agust 2017 in glass house Faculty of Agiculture, Mulawarman University, Samarinda. The pot experiment was designed Completely Randomized Design that consisted of four treatments level with seven replications. Treatment based on water avaibility (WA), those are : $A=494$ $\mathrm{ml}(50 \% \mathrm{WA}), \quad B=670 \mathrm{ml}(75 \%$ of WA $\mathrm{C}=846 \mathrm{ml}(100 \%$ of WA $)$ and $\mathrm{D}=1022 \mathrm{ml}(125 \%$ of WA).Each experiment pot contained $10 \mathrm{~kg}$ dried soil. The treated pots(after watering) have weight respectively, $A=10494 \mathrm{~g}, B=10670 \mathrm{~g}, C=10846 \mathrm{~g}$, and $D=11022 \mathrm{~g}$. These pots will be weighted every daycontinouslyduring plant growth and maintained those pot weight respectively.

Vegetative and generative data were collected and statistical analyzed using variance analysis. If the treatments showed significant different effect, the statistical analysis of those treatment continued by Least Significant Different (LSD) test at 5\% level to find out the optimum water requirement level. The results of the experiment showed that treatments of watering was significant effect on the average of vegetative parameters, (vegetative growth i.e.plant height at the age 20, 40, and 60 days, blooming after planting.) and significant effect for generative parameters (fruit number, length and fruit weight).

The optimum water requirement for eggplant at $506 \mathrm{ml} \mathrm{pot}^{-1}$ therefore during growth period eggplant needs $40,731 \mathrm{ml}$ of waterfor maximum yield.
\end{abstract}

Keywords : Water requirement, growth, eggplant

\section{PENDAHULUAN}

Terung (Solanum melogena L.) merupakan tanaman asli daerah tropis yang termasuk dalam golongan sayuran buah. Budidaya tanaman terung sudah lama dilaksanakan oleh petani, karena tanaman ini tidak memerlukan pemeliharaan khusus serta mempunyai data adaptasi yang tinggi terhadap ketinggian dan dapat diusahakan di dataran rendah maupun daratan tinggi.

Hasil produksi tanaman terung di provinsi Kalimantan Timur adalah 9,901 ton ha- ${ }^{1}$ (BPS, 2015).Rendahnya hasil produksi tersebut dikarenakan secara umum tanah di provinsi Kalimantan Timur didominasi oleh tanah ultisol yang sangat masam dan mempunyai tingkat kesuburan tanah yang rendah.Masalah tanah ultisol adalah reaksi tanah yang masam, kandungan AL yang tinggi, dan unsur hara yang rendah, sehingga diperlukan pemupukan yang baik agar tanah menjadi produktif.

Usaha meningkatkan hasil tanaman terung dapat ditempuh melalui penggunaan varietas unggul, pengaturan pola tanam, penambahan pupuk, atau dengan pengairan yang baik, hal ini disebabkan karena keadaan iklim di daerah Kalimantan Timur tidak tegasantara musim kemarau dan musim penghujan dan ditambahkan sering mengalami musim kemarau yang relatif panjang sehingga pemberiaan air pada tanaman harus diperhatikan agar jumlah air yang diberikan dapat mencukupi kebutuhan tanaman, namun tidak berlebihan sehingga dapat menghemat air, khususnya bagi tanaman terung yang memiliki daun lebar sehingga memerlukan jumlah air yang banyak untuk pertumbuhannya dan juga untuk kebutuhan transpirasi yang relatif besar. 
Tanaman terung sangat sensitif terhadap kekurangan air selama siklus pertumbuhannya.Tanaman ini mebutuhkan sejumlah air untuk pertumbuhan dan perkembangan.Respon tanaman terhadap kekurangan air bervariasi tergantung spesiesnya, umur tanaman dan kandungan air dalam tanah (Fu et al, 2013).

Zayova, et al, 2017 menambahkan kekurangan dan kelebihan air bagi tanaman sulit melangsungkan metabolism dengan baik. Pemberian air yang berlebihan pada tanaman terung dapat menyebabkan terung tumbuh memanjang, tanaman kurang mampu menyerap zat-zat hara, dan dapat menyebabkan tanaman mudah terserang penyakit layu bakteri, busuk leher akar, dan rebah semai, karena kelembaban tanah yang tinggi mendorong pertumbuhan dan perkembangan cendawan dan bakteri (Tsitsigiannis et al, 2008)

Muller, 2016 menambahkan Pemberian air yang kurang pada tanaman terung, juga akan menyulitkan tanaman melangsungkan aktivitas metabolismenya, transpirasi, traslokasi, unsur hara dengan baik. Tanaman terung yang kekurangan air akan tumbuh lambat, daun cepat tua, dan tanaman menderita klorosis.

Bila tingkat kekeringan berat dapat menyebabkan tajuknya layu. Kekurangan air selama pembungaan dapat menyebabkan kerontokan pada bunga. Demikian pula kekurangan air pada stadia pembentukan buah, juga dapat menyebabkan kerontokan buah (Cahyono, 2003 dan Ilahi, dkk., 2017). Tujuan penelitian ini adalah untuk megetahui respon tanaman terung terhadap pemberian air, untuk kebutuhan air bagi tanaman terung selama periode tumbuhnya.

\section{BAHAN DAN METODE}

Penelitian ini dilaksanakan pada 5 Mei sampai dengan 27 Agustus 2017 terhitung sejak penyemaian sampai panen, di Sempaja, Kecamatan Samarinda Utara. Penelitian ini menggunakan Rancangan acak lengkap (RAL) dan di ulang sebanyak 7 kali. Perlakuan berdasarkan ketersediaan air (WA) sebagai berikut: $\mathrm{A}=494 \mathrm{ml}$ air polybag ${ }^{-1}(50 \% \mathrm{WA}), \mathrm{B}=$ $670 \mathrm{ml}$ air polybag-1 $(75 \% \mathrm{WA}), \mathrm{C}=846 \mathrm{ml}$ air polybag $^{-1}(100 \% \mathrm{WA}), \mathrm{D}=1.022 \mathrm{ml}$ air polybag. Metode pemberian air pada pagi hari pukul $7 .^{00}$ sebelum disiram polybag berisi tanah dan tanaman ditimbang.Setelah diberi air sesuai dengan perlakuan polybag di timbang kembali. Pada sore hari pukul $5 .{ }^{00}$ polybag di timbang. Berat pada timbangan pada pagi hari setelah disiram air dikurangkan dengan berat pada penimbangan sore hari.Selisih keduanya merupakan air yang digunakan untuk transpirasi. Pada pagi hari berikutnya sebelum disiram Polibag ditimbang, berat polybag dan tanaman pada penimbangan kemaren sore dikurangkan dengan hasil penimbangan sebelum disiram pada pagi hari berikutnya, selisih keduanya merupakan karbohidrat yang digunakan untuk respirasi tanaman. Setelah disiram sesuaidengan perlakuan setiap polybag ditimbang kembali, begitu seterusnya. Prosedur penelitian meliputi ; pembuatan rumah plastik, persemaian, persemaian media tanam, penanaman dan pemeliharaan tanaman meliputi penyiraman, penyulaman, pengendalian gulma, pengendalian hama dan penyakit, dan panen. Pengambilan data dalam penelitian sebagai berikut : rata-rata tinggi tanaman $(\mathrm{cm})$ pada saat tanaman berumur 20,40 dan 60 hari setelah tanam (HST), umur tanaman saat berbunga $80 \%$ (hari), rata-rata jumlah buah $\operatorname{tanaman}^{-1}(\mathrm{bh})$, rata-rata luas daun $\left(\mathrm{cm}^{2}\right)$, ratarata kebutuhan air tanaman terung $\left(\mathrm{ml} \mathrm{hari}^{-1}\right)$, rata-rata kebutuhan karbohidrat untuk respirasi ( $\mathrm{g}$ hari $^{-1}$ ). Analisis data pengujian respon tanaman terung (solanum melongena L) terhadap pemberian air pada tanah ultisol dilakukan dengan menganalisis data hasil pengamatan sidik ragam.Pada hasil sidik ragam yang berbeda nyata dilakukan uji lanjutan BNT (Beda Nyata Kecil) taraf 5\%. Gomez and Gomez 1995.

\section{HASIL DAN PEMBAHASAN}

\section{Rata-Rata Dan Tinggi Tanaman}

Hasil pengamatan dan analisis dari perlakuan terhadap tinggi tanaman menunjukan bahwa perlakuan terhadap tinggi tanaman menunjukan bahwa perlakuan A $\left(494 \mathrm{ml} \mathrm{polybag}^{-1}\right), \mathrm{B}(670 \mathrm{ml}$ polybag- $\left.^{-1}\right), \mathrm{C}\left(864 \mathrm{ml} \mathrm{polybag}^{-1}\right)$ dan D $(1.022 \mathrm{ml}$ air polybag- ${ }^{1}$ ) saling berbeda nyata. Perlakuan $\mathrm{C}$ memberikan hasil yang lebih baik dari pada perlakuan lainnya diduga karena air yang diberikan pada perlakuan tersebut mencukupi kebutuhan air tanaman terung. (Solanum melongena L.)pada fase pertumbuhan awal sampai akhir, Cahyono (2003), menyatakan bahwa kebutuhan air terbanyak pada tanaman terung adalah pada stadia awal (fase pertumbuhan vegetatif), stadia pembungaan (fase tanaman 
berbunga), dan stadia pembentukan hasil (fase tanaman berbuah). Sarker dan Hara (2011) menambahkan hal ini menyebabkan tebatasnya unsur hara yang terlarut dalam tanah sehingga air sebagai suatu pelarut adalah pembawa hara dan $\mathrm{O}_{2}$ ke sel-sel organisme yang hidup. Selanjutnya Hardjowigwno (2010), air berperan bagi pertumbuhan tanaman karena mengandung unsur hara bagi tanaman, pelarut unsur hara, dan sebagai bagian dari sel-sel tanaman (protoplasma). Sedangkan pada perlakuan D jumlah air yang diberikan terlalu banyak sehingga menggangu akar dalam menyerap unsur hara dan juga menyebabkan berkurangnya oksigen di dalam tanah. Keadaan tanah yang terlalu basah dan tergenangmenyebabkan kerusakan pada akar karena menyebabkan akar tanaman menjadi busuk, yang kemudian menggangu kegiatan metabolisme tanaman karena menyebabkan unsur hara dan air oleh akar juga terganggu,hal ini dapat menyebabkan tanaman menjadi layu bahkan mati.
Ditambah oleh Cahyono (2003), pemberian air yang berlebihan pada tanaman terung dapat menyebabkan tanaman kurang mampu menyerap zat-zat hara. Muller, et al (2016) menyatakan bahwapemberian air yang berlebihan akan menyebabkan kelayuan dan kematian pada tanaman, selain itu kelebihan air dalam tanah menyebabkan sirkulasi udara (aerasi) di dalam tanah kurang baik sehingga oksigen didalam tanah berkurang dan tanah menjadi anaerob. Hasil pengamatan dari perlakuan terhadap umur tanaman saat berbunga $80 \%$ menunjukan perbedaan sangat nyata, pada perlakuan C (864 $\mathrm{mL}$ air) tanaman lebih cepat berbunga dari pada perlakuan lainnya. Hal ini menandakan bahwa jumlah air yang diberikan pada perlakuan $\mathrm{C}$ mencukupi kebutuhan tanaman pada masa generatifnya. Pengaruh pemberian air terhadap rata tinggi tanaman umur 20, 40, 60 (HST) dan saat berbunga $80 \%$ disajikan pada Tabel 1

Tabel 1. Pengaruh pemberian air terhadap rata-rata tinggi tanaman umur 20, 40, 60 (HST) dan umur berbunga $80 \%$.

\begin{tabular}{cccrc}
\hline \multirow{2}{*}{ Perlakuan } & \multicolumn{3}{c}{ Tinggi Tanaman } & \multirow{2}{*}{ Umur Berbunga 80\% } \\
\cline { 2 - 4 } & 20 Hari & 40 Hari & 60 Hari & \\
A & $20,49 \mathrm{~b}$ & $60,39 \mathrm{c}$ & $82,71 \mathrm{~b}$ & $26,86 \mathrm{~b}$ \\
$\mathrm{~B}$ & $22,14 \mathrm{a}$ & $62,83 \mathrm{c}$ & $88,29 \mathrm{~b}$ & $26,14 \mathrm{~b}$ \\
$\mathrm{C}$ & $23,14 \mathrm{a}$ & $69,10 \mathrm{a}$ & $101,73 \mathrm{a}$ & $25,43 \mathrm{a}$ \\
$\mathrm{D}$ & $22,29 \mathrm{a}$ & $67,56 \mathrm{ab}$ & $99,19 \mathrm{a}$ & $25,57 \mathrm{a}$
\end{tabular}

Keterangan : Angka yang diikuti huruf yang sama menunjukkan perlakuan tidak berbeda nyata BNT 5\% $(20 \mathrm{hst})=1,65(40 \mathrm{hst})=5,20(60 \mathrm{hst})=7,75($ umur berbunga hst $)=0,75$

\section{Rata-rata jumlah, panjang, dan berat buah dan luas daun pertanaman}

Hasil pengamatan dari perlakuan A(494 $\mathrm{ml}$ air) dan $\mathrm{B}(670 \mathrm{ml}$ air) terhadap rata-rata jumlah buah, panjang buah, dan berat buah tidak berbeda nyata, hal ini diduga karena jumlah air yang diberikan tidak mencukupi untuk mempertahankan buah pada batang tanaman dan tidak dapat mendukung pertambahan panjang dan berat buah. Hal ini disebabkan tanaman terung berdaun lebar maka air yang diserap sebagian besar ditranspirasikan oleh tanaman dan sisanya digunakan tanaman untuk kebutuhan hidupnya dan jumlah itu tidak cukup untuk pembentukan buah dan mempertahankannya agar tidak gugur serta untuk pertambahan panjang dan berat buah. Seperti yang dikemukakan oleh Hakim dkk., (1986), air yang di ambil tanaman dari dalam tanah sebagian besar ditranspirasikan, sebagian ditahan dalam bentuk cairan sel dan sebagian dipecahkan untuk diambil hidrogennya dan mungkin juga oksigennya untuk menyusun karbohidrat. Kekurangan air umumnya menyebabkan kerusakan yang paling berat bila dibandingkan dengan faktor lain. Shanti (1982) menambahkan bahwa kekurangan air juga dapat menyebab berkurangnya fotosintesis sehingga hasil menurun, karena untuk dapat berproduksi dengan baik tanaman memerlukan air dalam jumlah tertentu. pada batang tanaman dan tidak dapat mendukung pertambahan panjang dan berat buah.

Hal ini disebabkan tanaman terung berdaun lebar maka air yang diserap sebagian besar ditranspirasikan oleh tanaman dan sisanya digunakan tanaman untuk kebutuhan hidupnya dan jumlah itu tidak cukup untuk pembentukan buah dan mempertahankannya agar tidak gugur serta untuk pertambahan panjang dan berat buah. 
Seperti yang dikemukakan oleh Hakim dkk., (1986), air yang di Ditambah oleh Harjiwegeno (2010) dan Sarker \& Hara (2011), air sebagai pelarut berfungsi sebagai pembawa $\mathrm{O}_{2}$ ke sel-sel organisme yang hidup. Pada tanaman, air sangat diperlukan untuk reaksi dalam proses-proses fotosintesis dan hidrolisis serta mempertahankan turgor sel. Pada perlakuan C (846 ml air) dan D (1022 ml air) menunjukan perbedaan nyata dibandingkan perlakuan A (494 ml air) dan B $(670 \mathrm{ml}$ air) disajikan pada tabel 2. Peningkatan pada hasil tanaman disebabkan cukup tersedia air untuk pertumbuhan generative tanaman seperti bertambahnya jumlah, panjang dan berat buah. Termasuk rata rata luas daun. Perlakuan C (846 $\mathrm{ml}$ air) menunjukan luas daun terlebar yaitu $536,65 \mathrm{~cm} 2$, dibandingkan perlakuan $\mathrm{A}, \mathrm{B}$, dan D. Hal ini disebabkan pada perlakuan $C$ cukup tersedia air untuk pembentukan daun tanaman, sedangkan perlakuan A dan B terbatas jumlah air untuk pertumbuhan dan perkembangan daun. Pada perlakuan D tanaman mengalami kelebihan air sehingga ketersediaan oksigen terbatas untuk respirasi akar dalam tanah. Hal ini berpengaruh buruk terhadap pertumbuhan tanaman. Cahyono (2003) dan Ilahi (2017) menyampaikan bila pemberian air cukup dalam tanah maka akan meningkatkan pertumbuhan tanaman, seperti tinggi tanaman, jumlah tanaman, luas daun, jumlah panjang dan berat buah (tabel 2).

Tabel 2. Pengaruh pemberian air terhadap rata-rata jumlah, panjang, berat buah dan luas daun.

\begin{tabular}{ccccc}
\hline \multirow{2}{*}{ Perlakuan } & \multicolumn{4}{c}{ Pengaruh Pemberian Air } \\
\cline { 2 - 5 } & $\begin{array}{c}\text { Jumlah Buah } \\
(\text { Biji })\end{array}$ & $\begin{array}{c}\text { Panjang Buah } \\
(\mathrm{cm})\end{array}$ & $\begin{array}{c}\text { Berat Buah } \\
(\mathrm{g})\end{array}$ & $\begin{array}{c}\text { Luas Daun } \\
\mathrm{cm}^{2}\end{array}$ \\
\hline & & & & \\
$\mathrm{A}$ & $5,71 \mathrm{~b}$ & $8,70 \mathrm{~b}$ & $0,81 \mathrm{~b}$ & $228,92 \mathrm{~d}$ \\
$\mathrm{~B}$ & $7,86 \mathrm{~b}$ & $10,84 \mathrm{~b}$ & $1,13 \mathrm{~b}$ & $340,46 \mathrm{c}$ \\
$\mathrm{C}$ & $10,93 \mathrm{a}$ & $15,94 \mathrm{a}$ & $1,89 \mathrm{a}$ & $526,65 \mathrm{a}$ \\
$\mathrm{D}$ & $8,86 \mathrm{a}$ & $11,49 \mathrm{a}$ & $1,22 \mathrm{a}$ & $417,58 \mathrm{~b}$
\end{tabular}

Keterangan : Angka rata-rata diikuti huruf yang sama menunjukkan berbeda tidak nyata pada uji BNT 5\% $(A=1,45, B=2,20, C=0.60, D=16,78)$.

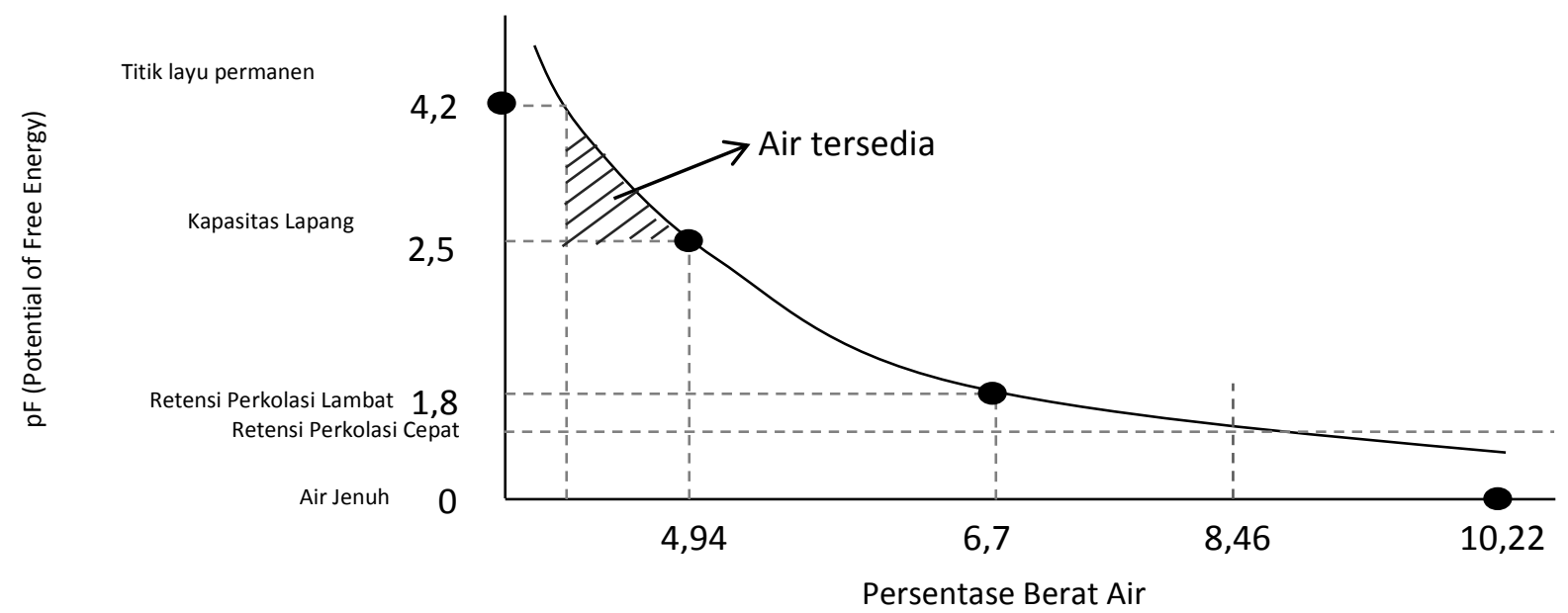

Gambar 1. Karateristik Air Pada Tekstur Tanah Lempung Liat Berpasir

Tabel 3. Rata-rata kebutuhan air tanaman terung (Solanum melogena L.) pada fase pertumbuhan (ml).

\begin{tabular}{cccccc}
\hline \multirow{2}{*}{ Pertumbuhan } & \multicolumn{4}{c}{ Perlakuan (ml/polybag) } & \multirow{2}{*}{ Rata - rata } \\
\cline { 2 - 5 } & $\mathrm{A}(494)$ & $\mathrm{B}(670)$ & $\mathrm{C}(846)$ & $\mathrm{D}(1022)$ & \\
\hline Awal & 196 & 221 & 225 & 221 & 216 \\
Perkembangan Tanaman & 268 & 316 & 437 & 358 & 345 \\
Pertengahan & 375 & 489 & 658 & 501 & 506 \\
Akhir & 298 & 347 & 468 & 339 & 363 \\
\hline Rata - rata & 285 & 343 & 447 & 355 & \\
\hline
\end{tabular}


Tabel 4. Kebutuhan air tanaman terung selama siklus pertumbuhan (ml).

\begin{tabular}{lcr}
\hline Fase pertumbuhan & Jumlah hari x air & ml \\
\hline Fase awal pertumbuhan & $25 \times 216$ & 5.400 \\
Fase perkembangan & $30 \times 345$ & 10.350 \\
Fase pertengahan & $30 \times 506$ & 15.180 \\
Fase pertumbuhan akhir & $27 \times 363$ & 9.801 \\
\hline Total & & 40.731 \\
\hline
\end{tabular}

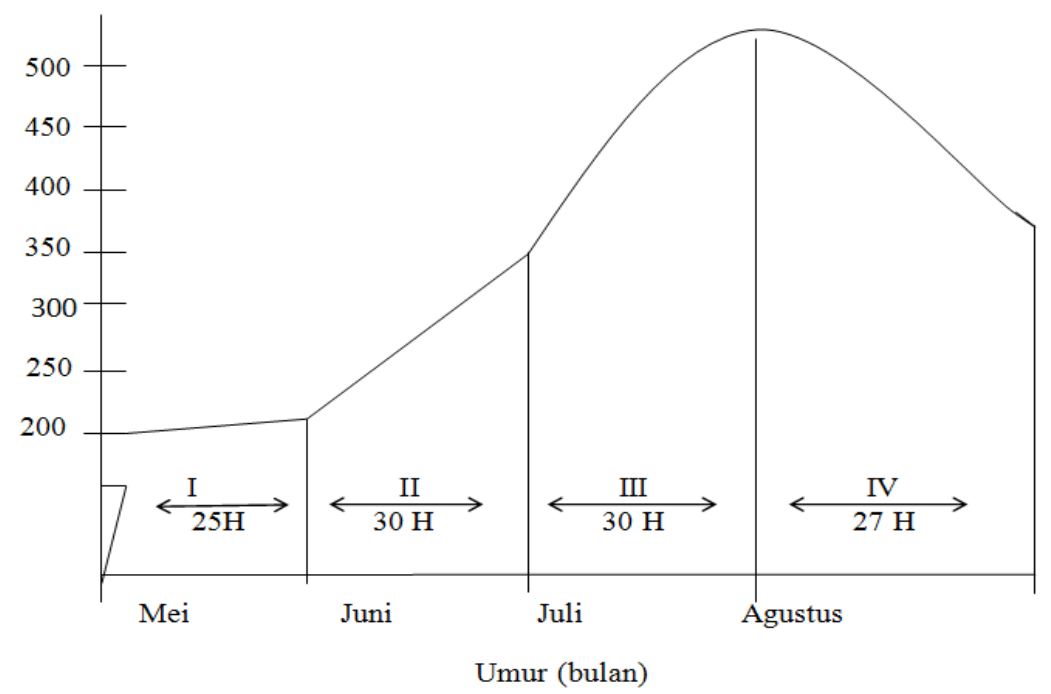

Gambar 2. Kebutuhan Air Tanaman Terung selama pertumbuhan

\section{Rata-rata kebutuhan karbohidrat untuk respirasi}

Pada penimbangan sore hari dan pagi hari berikutnya terdapat selisih berat yang menandakan hilangnya karbohidrat pada saat malam hari tersebut. Karbohidrat yang hilang tersebut yang digunakan dalam proses respirasi, jumlah karbohidrat yang direspirasikan terus meningkat pada setiap fase pertengahan dan kemudian menurun setelah tanaman memasuki fase pertumbuhan akhir. Ditambah oleh Sarker \& Hara (2011), bahwa respirasi jaringan tumbuhan dipengaruhi oleh suhu, kelembaban, adanya luka, konsentrasi karbondioksida dan oksigen, umur dan jenis jaringan, banyaknya makanan yang tersedia, dan faktor-faktor lain. Proses respirasi dapat ditampilkan dengan reaksi berikut ini:

$$
\mathrm{C}_{6} \mathrm{H}_{12} \mathrm{O}_{6}+6 \mathrm{O}_{2} \rightarrow 6 \mathrm{CO}_{2}+6 \mathrm{H}_{2} \mathrm{O}+\mathrm{E}
$$

Bukti adanya respirasi adalah terjadinya perubahan suhu, pengunaan oksida pembebasan karbon, dan penurunan berat. Perbedaan berat menunjukan karbohidrat yang hilang respirasi. Rata-rata kebutuhan karbohidrat pada siklus pertumbuhan disajikan pada Tabel 5 .

Tabel 5. Rata-rata kebutuhan Karbohidrat pada setiap fase Pertumbuhan

\begin{tabular}{|c|c|c|c|c|c|}
\hline \multirow{2}{*}{ Pertumbuhan } & \multicolumn{4}{|c|}{ Perlakuan } & \multirow{2}{*}{ Rata - rata } \\
\hline & $\mathrm{A}$ & $\mathrm{B}$ & $\mathrm{C}$ & $\mathrm{D}$ & \\
\hline Awal & 50 & 50 & 50 & 50 & 50 \\
\hline Perkembangan Tanaman & 101 & 105 & 110 & 107 & 106 \\
\hline Pertengahan & 149 & 168 & 189 & 170 & 169 \\
\hline Akhir & 112 & 116 & 122 & 118 & 117 \\
\hline Rata - rata & 103 & 110 & 118 & 111 & \\
\hline
\end{tabular}




\section{KESIMPULAN}

1. Perlakuan pemberian air menunjukkan pengaruh yang berbeda nyata terhadap pertumbuhan vegetative dan generative

2. Perlakuan pemberian air menunjukkan pengaruh yang berbeda nyata terhadap pertumbuhan vegetative dan generative

3. Kebutuhan air optimum pada perlakuan $\mathrm{C}$ sebesar $506 \mathrm{ml}$ air

4. Kebutuhan air tanaman terung selama siklus pertumbuhan sebesar $40.731 \mathrm{ml}$

\section{DAFTAR PUSTAKA}

Cahyono, B. 2003.Tanaman terung (Teknik Budidaya Dan Analisis Usaha Tani).CV Aneka Ilmu. Semarang.

Doorenbos.J and W. O Pruitt. 1997. Guidelines for Predicting Crop water requirements. Food and Agriculture Organization of the United Nation, Rome.

Fu. S.Q, Yang .C.R, Wang.S.H, Zhao. B. Zhou. L.C. Ren. X.S, Gou.D.Y. 2013.Leaf morphological and ultrastructural performance of eggplant (Solanum melongena $L$.) in response to water stress. Journal Photosynthetica 51 (1):109-114. China.

Gomez, K. A and Gomez, A.A 1995. Prosedur Statistik dan Penelitian.Diterjemahkan oleh Syamsyudin, E dan Baharsyah, J, Edisi kedua Uuniversitas Indonesia Press Jakarta.

Hakim, N, n.y. Nyalepa, A. N Lubin, S. G, Nugroho, M, R Soul, N. A Dika, G. B Hong, H. H Baiky 1986. Dasar-dasar Ilmu Tanah Universitas Lampung.

Hardjowigeno, S. 2010. Ilmu Tanah. Akademika Praindo Jakarta.

Ilahi.K.N.R， Isda.N.M， Rosmaina. 2017. Vegetative Growth Response to Drought Stress in Eggplant. International Conference on Biology and Enviromental Science. Indonesia.

Lakitan B. 2013. Dasar-dasar Fisiologi Tumbuhan. PT. Raja Granfindo Pusada, Jakarta.
Meyer B. S and B. B Anderson 1965. Land Physiology $2^{\text {nd }} e d$. Van Nostrand Co. Juc Toranto.

Muller. T, Bouleau R, Perona. P (2016). Optimizing drip irrigation for eggplant crops in semi-arid zones using evolving thresholds. J. Agriculture Water Management 177 (2016) 54-65. Lausanne, Switzerland.

Sarker C. B and Hara M (2011). Effect of Elevated $\mathrm{CO} 2$ and Water Stress on the Adaption of Stomata and Gas Exchange in Leaves of Eggplants (Solanum Melongena L). Bangladesh J. Bot. 40 (1) : 1-8, 2011 (June).

Sarief, S 1984. Fisika dan Kimia Tanah Pertanian. Pustaka Buana Bandung.

Shanti.R (1982).Water Requirement for Some Tropical Crops. Thesis Post Graduate International Trainning Center (ITC). University of Ghent, Belgium.

Tsitsigiannis. I. D, Antonio. P, Tjamos. E. S, Paplomatas. J. E (2008). Major Diseases of Tomato, Paper and Eggplant in Grennhouses.The Eropean Journal of Plan Science and Biotecnology.Athene Greece.

Zayova. E, Philipov. P, Nedev, T, Stoeva. D (2017).Response of in vitroCultivated eggplant (Solanum melongena L.) to salt and Drought Stress.Agrolife Scientific Journal-Volume 6 No. 1, 2017. 